\title{
Risk factors for wound-related reoperations in patients with metastatic spine tumor
}

\author{
*Hannah M. Carl, BS,,2 A. Karim Ahmed, BS, ${ }^{1}$ Nancy Abu-Bonsrah, MD, ${ }^{1}$ \\ Rafael De la Garza Ramos, MD, ${ }^{1}$ Eric W. Sankey, MD, ${ }^{3}$ Zachary Pennington, BS, ${ }^{1}$ Ali Bydon, MD, ${ }^{1}$ \\ Timothy F. Witham, MD, ${ }^{1}$ Jean-Paul Wolinsky, MD, ${ }^{1}$ Ziya L. Gokaslan, MD, ${ }^{4}$ \\ Justin M. Sacks, MD, MBA, ${ }^{2}$ C. Rory Goodwin, MD, PhD, ${ }^{3}$ and Daniel M. Sciubba, MD ${ }^{1}$
}

\begin{abstract}
Departments of ${ }^{1}$ Neurosurgery and ${ }^{2}$ Plastic and Reconstructive Surgery, The Johns Hopkins University School of Medicine, Baltimore, Maryland; ${ }^{3}$ Department of Neurosurgery, Duke University Medical Center, Durham, North Carolina; and ${ }^{4}$ Department of Neurosurgery, The Warren Alpert Medical School of Brown University, Providence, Rhode Island
\end{abstract}

\begin{abstract}
OBJECTIVE Resection of metastatic spine tumors can improve patients' quality of life by addressing pain or neurological compromise. However, resections are often complicated by wound dehiscence, infection, instrumentation failures, and the need for reoperation. Moreover, when reoperations are needed, the most common indication is surgical site infection and wound breakdown. In turn, wound reoperations increase morbidity as well as the length and cost of hospitalization. The aim of this study was to examine perioperative risk factors associated with increased rate of wound reoperations after metastatic spine tumor resection.
\end{abstract}

METHODS A retrospective study of patients at a single institution who underwent metastatic spine tumor resection between 2003 and 2013 was conducted. Factors with a p value $<0.200$ in a univariate analysis were included in the multivariate model.

RESULTS A total of 159 patients were included in this study. Karnofsky Performance Scale score > 70, smoking status, hypertension, thromboembolic events, hyperlipidemia, increasing number of vertebral levels, and posterior approach were included in the multivariate analysis. Thromboembolic events $(95 \% \mathrm{Cl} 1.19-48.5, p=0.032)$ and number of levels involved were independently associated with increased wound reoperation rates in the multivariate model. For each additional spinal level involved, the risk for wound reoperations increased by $21 \%(95 \% \mathrm{Cl} 1.03-1.43, p=0.018)$.

CONCLUSIONS Although wound complications and subsequent reoperations are potential risks for all patients with metastatic spine tumor, due to adjuvant radiotherapy and other medical comorbidities, this study identified patients with thromboembolic events or those requiring a larger incision as being at the highest risk. Measures intended to decrease the occurrence of perioperative venous thromboembolism and to improve wound care, especially for long incisions, may decrease wound-related revision surgeries in this vulnerable group of patients.

https://thejns.org/doi/abs/10.3171/2017.10.SPINE1765

KEY WORDS reoperation; spine tumor; metastasis; wound dehiscence; infection; instrumentation failure; oncology

$\mathrm{T}$ HE most common indications for surgical treatment of metastatic spine lesions include spinal instability, local tumor control, management of intractable pain, and prevention of neurological deterioration. $.^{22,25} \mathrm{Al}-$ though surgery for metastatic spine disease is primarily palliative in nature, recent studies have demonstrated that this intervention can significantly improve patients' quality of life. ${ }^{33}$ Despite the benefits of treatment, the potential complications associated with surgery for metastatic spine disease represent a significant source of morbidity and mortality. ${ }^{15,19,33}$ These include wound infections, wound dehiscence, hematomas, neurological impairments, deep venous thrombosis, and instrumentation failure, among others. ${ }^{15,33}$

In patients with metastatic spine tumors, overall complication rates range between $19 \%$ and $28 \%, 30,33,34$ whereas

ABBREVIATIONS BMI = body mass index; $\mathrm{CAD}=$ coronary artery disease $; \mathrm{COPD}=$ chronic obstructive pulmonary disease; $\mathrm{DM}=$ diabetes mellitus; $\mathrm{EBL}=$ estimated blood loss; KPS = Karnofsky Performance Scale; RT = radiation therapy; VEGF = vascular endothelial growth factor; VTE = venous thromboembolism.

SUBMITTED January 16, 2017. ACCEPTED October 4, 2017.

INCLUDE WHEN CITING Published online March 16, 2018; DOI: 10.3171/2017.10.SPINE1765.

* H.M.C., A.K.A., and N.A.B. contributed equally to this work. 
the incidence of surgical site infection and wound breakdown is $4 \%-20 \%{ }^{8,20,23,26}$ Crucially, the most common reason for reoperation after the resection of spinal metastases is surgical site infection, which commonly leads to wound breakdown. ${ }^{26}$ Spinal tumor resections are further complicated by the fact that many patients have had previous radiotherapy or repeated surgeries, which diminish the capacity for wound healing following tumor resection. ${ }^{10,13}$ Patient demographic information and comorbidities such as body mass index (BMI), diabetes mellitus (DM), smoking status, end-stage renal disease, and a recently created frailty index have also been shown to increase the risk of postoperative complications after spine surgery. ${ }^{2-4,6,7,12,21}$

Given the risk for possible neurological damage as well as exposed or infected hardware, wound breakdown is a particularly serious complication for patients with spine tumors. Therefore, for patients who underwent resection of metastatic spine tumor, we aimed to identify factors associated with wound dehiscence that required reoperation. Demographics, medical comorbidities, and surgical variables were analyzed.

\section{Methods}

\section{Study Design and Patients}

This study was a retrospective review of patients with metastatic spine disease and was approved by our institutional review board. Included patients were seen at our institution (Johns Hopkins) and treated within the neurosurgery department over a 10-year period (2003-2012). Patients who were included in the study satisfied the following criteria: 1) age $18-100$ years at the time of surgery; 2) minimum of 3 months of follow-up after their initial operation; 3) complete electronic medical record; and 4) resection of a metastatic spine lesion with the primary consisting of lung, breast, kidney, bone marrow (multiple myeloma or plasmacytoma), prostate, colorectal, gynecological (uterus or cervix), or skin (melanoma) - as these were more frequent tumor types seen in this cohort ( $\mathrm{n} \geq 5$ patients).

\section{Study Variables}

The primary outcome variable in this study was wound breakdown that required reoperation. To capture possible effects of postoperative radiation treatments or chemotherapy regimens, we included any wound reoperation that occurred during the patient's life. Predictor variables considered in this study included demographic variables (age, BMI, race); medical variables (smoking status, hypertension, coronary artery disease [CAD], thromboembolic events, renal disease, DM, preoperative albumin, hyperlipidemia, chronic obstructive pulmonary disease [COPD]); surgical variables (previous spine irradiation, approach [anterior, posterior, combined], estimated blood loss [EBL], number of spinal levels involved in operation); steroid administration; topical and parenteral antibiotics; vascular endothelial growth factor (VEGF) inhibitor treatment; postoperative radiation therapy (RT); chemotherapy; and Karnofsky Performance Scale (KPS) score.

\section{Statistical Analysis}

General demographic data are presented as the mean \pm SD. Wound reoperations are presented as the percentage of patients with at least one wound reoperation. Frequencies were compared via the chi-square test and means were compared via 1-way ANOVA. For time to wound reoperation failure-event analysis, failure was defined as wound reoperation, and the log-rank test was used to compare curves stratified by tumor type. Additionally, survival with just wound reoperation as the primary end point was analyzed. A multivariate Cox proportional hazards model was used to identify independent factors associated with wound reoperation; factors with a $p$ value $<0.200$ on univariate analysis were included in a multivariate model. The confidence interval was set to $95 \%$; results of this model are presented as odds ratios with $95 \%$ CIs. Statistical significance was defined as a p value $<0.05$. All analyses were done in Stata/SE 12 (StataCorp LP) or GraphPad Prism 6 (GraphPad Software, Inc.).

\section{Results}

\section{Demographic Information}

A total of 159 patients were included in the study. The average age for the overall cohort was $59.6 \pm 11.7$ years, and $85(53.5 \%)$ of the patients were men. Surgery was performed by a neurosurgeon in all cases. General demographic information is presented in Table 1. Of the 159 patients included, 22 underwent wound reoperation. Six of the 22 surgeries were related to wound dehiscence, and the remaining 16 were for wound infections. There were no significant factors in comparisons between the 2 groups requiring wound reoperation.

\section{Factors Associated With Reoperation \\ Univariate Analysis}

Patients with a KPS score $\geq 70$ were $67 \%$ less likely to have a reoperation due to wound breakdown than were patients with a KPS score $<70(\mathrm{p}=0.025)$. Additionally, patients with an increasing number of spinal levels involved in the operation were at a higher risk for reoperation, such that for every increase in spinal levels involved, the risk of reoperation increased by $20 \%(\mathrm{p}=0.008)$. Presence of a venous thromboembolism (VTE) approached significance for an increased risk for reoperation $(p=0.06)$. Other factors with a $\mathrm{p}$ value $<0.200$ that met inclusion criteria for the multivariate model were smoking status, hypertension, hyperlipidemia, and a posterior surgical approach (Table 2).

\section{Multivariate Analysis}

All 7 factors with a p value $<0.200$ in univariate analysis were included in the multivariate model. In the multivariate analysis, KPS score, smoking status, hypertension, hyperlipidemia, and posterior surgical approach dropped out of the model-leaving VTEs and increasing number of levels as independent risk factors for a significantly higher rate of wound-related reoperations (Table 3). Patients with a VTE had wound reoperations 7.61 times more often than patients without a VTE (95\% CI 1.19-48.5, $\mathrm{p}=0.032)$. For each additional spinal level involved in the tumor resection surgery, the risk for wound reoperation increased by $21 \%(95 \%$ CI $1.03-1.43, \mathrm{p}=0.018)$. 
TABLE 1. Demographic data in 159 patients who underwent surgery for metastatic spine tumor

\begin{tabular}{|c|c|c|}
\hline Parameter & $\begin{array}{c}\text { No Wound } \\
\text { Reop, } n=137\end{array}$ & $\begin{array}{l}\text { Wound Reop, } \\
\quad n=22\end{array}$ \\
\hline Mean age in yrs (range) & $59.79(27-89)$ & $58.45(42-80)$ \\
\hline Male sex, no. $(\%)$ & $74(54.0)$ & $11(50.0)$ \\
\hline \multicolumn{3}{|l|}{ Race, no. (\%) } \\
\hline Caucasian & $97(70.8)$ & $17(77.3)$ \\
\hline African American & $29(21.2)$ & $5(22.7)$ \\
\hline Other & $11(8.0)$ & $0(0)$ \\
\hline Mean BMI (no. of patients) & $27.7(74)$ & $27.6(19)$ \\
\hline $\begin{array}{l}\text { Mean preop albumin, g/L (no. of } \\
\text { patients)* }\end{array}$ & $3.87(112)$ & $3.81(14)$ \\
\hline $\begin{array}{l}\text { Topical antibiotics/vancomycin, } \\
\text { no. }(\%) \dagger\end{array}$ & $130(100)$ & $20(100)$ \\
\hline Parenteral antibiotics, \% (no.)‡ & $98.6(69 / 70)$ & $92.9(13 / 14)$ \\
\hline $\mathrm{EBL}$ in $\mathrm{ml}$ & 1648 & 2240 \\
\hline Duration of symptoms, days $\mathbb{I}$ & 95 & 90 \\
\hline VEGF inhibitor treatment, no. $(\%)^{* *}$ & $19(14.5)$ & $0(0)$ \\
\hline \multicolumn{3}{|l|}{ Primary tumor type, no. (\%) } \\
\hline Breast & $25(18.2)$ & $6(27.3)$ \\
\hline Cervix & $2(1.5)$ & $0(0)$ \\
\hline Colorectal & $8(5.8)$ & $6(27.3)$ \\
\hline Uterus & $5(3.6)$ & $0(0)$ \\
\hline Melanoma & $7(5.1)$ & $0(0)$ \\
\hline Multiple myeloma/plasmacytoma & $20(14.6)$ & $1(4.5)$ \\
\hline Lung & $31(22.6)$ & $4(18.2)$ \\
\hline Prostate & $14(10.2)$ & $4(18.2)$ \\
\hline Kidney & $25(18.2)$ & $1(4.5)$ \\
\hline \multicolumn{3}{|l|}{ Spine lesion location, no. (\%) } \\
\hline Cervical & $32(23.4)$ & $2(9.1)$ \\
\hline Thoracic & $83(60.6)$ & $18(81.8)$ \\
\hline Lumbar & $34(24.8)$ & $5(22.7)$ \\
\hline Sacral & $2(1.5)$ & $1(4.5)$ \\
\hline Combined & $14(10.2)$ & $4(18.2)$ \\
\hline \multicolumn{3}{|l|}{ Metastases \& recurrence, no. (\%) } \\
\hline Extraspinal bony metastases & $51(37.2)$ & $11(50.0)$ \\
\hline Visceral metastases & $57(41.6)$ & 7 (31.8) \\
\hline Brain metastases & $17(12.4)$ & $3(13.6)$ \\
\hline Recurrence of spine lesion & $13(9.5)$ & $4(18.2)$ \\
\hline \multicolumn{3}{|l|}{ Presentation, no. (\%) } \\
\hline Preop motor deficit & $74(54)$ & $14(63.6)$ \\
\hline Preop sensory deficit & $65(47.4)$ & $11(50.0)$ \\
\hline Preop pain & $125(91.2)$ & $18(81.8)$ \\
\hline Preop gait dysfunction & $55(40.1)$ & $12(54.5)$ \\
\hline Preop bladder dysfunction & $10(7.3)$ & $0(0)$ \\
\hline Preop bowel dysfunction & $5(3.6)$ & $1(4.5)$ \\
\hline \multicolumn{3}{|l|}{ Comorbidities, no. (\%) } \\
\hline Smoker†† & $53(42.4)$ & $10(50.0)$ \\
\hline Hypertension & $50(36.5)$ & $6(27.3)$ \\
\hline CAD & $16(11.7)$ & $4(18.2)$ \\
\hline Cardiovascular disease & $9(6.6)$ & $6(27.3)$ \\
\hline
\end{tabular}

» CONTINUED FROM PREVIOUS COLUMN

TABLE 1. Demographic data in 159 patients who underwent surgery for metastatic spine tumor

\begin{tabular}{|c|c|c|}
\hline Parameter & $\begin{array}{c}\text { No Wound } \\
\text { Reop, } n=137\end{array}$ & $\begin{array}{c}\text { Wound Reop, } \\
\qquad n=22\end{array}$ \\
\hline \multicolumn{3}{|l|}{ Comorbidities, no. (\%) (continued) } \\
\hline Thromboembolic disease & $8(5.8)$ & $4(18.2)$ \\
\hline Renal disease & $3(2.2)$ & $1(4.5)$ \\
\hline $\mathrm{DM}$ & $22(16.1)$ & $3(13.6)$ \\
\hline Hyperlipidemia & $31(22.6)$ & $2(9.1)$ \\
\hline COPD & $13(9.5)$ & $2(9.1)$ \\
\hline \multicolumn{3}{|l|}{ 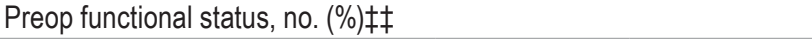 } \\
\hline KPS score $\geq 70$ & $106(79.7)$ & $15(68.2)$ \\
\hline KPS score $\geq 40$ & $20(15.0)$ & $6(27.3)$ \\
\hline KPS score $<40$ & $7(5.3)$ & $1(4.5)$ \\
\hline \multicolumn{3}{|l|}{ Surgery } \\
\hline $\begin{array}{l}\text { Mean no. of levels instrumented } \\
\text { (range) }\end{array}$ & $5.02(0-14)$ & $7.05(0-14)$ \\
\hline \multicolumn{3}{|l|}{ Approach, no. (\%) } \\
\hline Anterior & $39(28.5)$ & $2(9.1)$ \\
\hline Posterior & $87(63.5)$ & $18(81.8)$ \\
\hline Combined & $11(8.0)$ & $2(9.1)$ \\
\hline Periop complications, no. (\%) & $64(46.7)$ & $12(54.5)$ \\
\hline \multicolumn{3}{|l|}{ Radiation, no. (\%) } \\
\hline Preop radiation to primary tumor & $41(29.9)$ & $10(45.5)$ \\
\hline Preop radiation to spine & $51(37.2)$ & $12(54.5)$ \\
\hline Postop radiation to spine & $69(50.4)$ & $6(27.3)$ \\
\hline Postop cEBRT & $64(46.7)$ & $6(27.3)$ \\
\hline Postop SRS & $5(3.6)$ & $0(0)$ \\
\hline \multicolumn{3}{|l|}{ Steroids, no. (\%) } \\
\hline Preop steroids & $80(58.4)$ & $9(40.9)$ \\
\hline Postop steroids & $46(33.6)$ & $7(31.8)$ \\
\hline \multicolumn{3}{|l|}{ Chemotherapy, no. (\%) } \\
\hline Preop chemotherapy & $60(43.8)$ & $12(54.5)$ \\
\hline Postop chemotherapy & $66(48.2)$ & $10(45.5)$ \\
\hline \multicolumn{3}{|l|}{ Survival from surgery } \\
\hline Mean survival in mos (range)§§ & $13.3(0.1-73)$ & $9.2(1.1-41.8)$ \\
\hline
\end{tabular}

cEBRT = conventional external-beam RT; SRS = stereotactic radiosurgery.

* Preoperative albumin was known for 14 patients requiring wound reoperations and 112 not requiring wound reoperations.

† Topical antibiotics were known for 130 patients not requiring wound reoperations and 20 requiring wound reoperations.

‡ Status of parenteral antibiotics was known for 70 patients not undergoing wound reoperations and 14 undergoing wound reoperations.

$\S$ The EBL was known for 81 patients not requiring wound reoperations and 10 requiring wound reoperations.

II Duration of symptoms was known for 118 patients not requiring wound reoperations and 18 requiring wound reoperations.

** Treatment with VEGF inhibitors was known for 131 patients not requiring wound reoperations and 14 requiring wound reoperations.

†† Smoking status was known for 125 patients not undergoing wound reoperations and 20 undergoing wound reoperations.

执 Baseline KPS score available for 133 of 137 patients not undergoing wound reoperations.

$\S \S$ Survival known for 87 patients not undergoing wound reoperations and 9 undergoing wound reoperations. 
TABLE 2. Univariate analysis of factors associated with wound reoperation

\begin{tabular}{|c|c|c|}
\hline Parameter & OR $(95 \% \mathrm{Cl})$ & $\mathrm{p}$ Value \\
\hline Increasing age & $0.99(0.96-1.03)$ & 0.870 \\
\hline Age $>65$ yrs & $1.26(0.50-3.15)$ & 0.612 \\
\hline Male sex & $0.85(0.34-2.09)$ & 0.726 \\
\hline \multicolumn{3}{|l|}{ Race } \\
\hline Caucasian & Reference & \\
\hline African American & $0.71(0.22-2.26)$ & 0.564 \\
\hline Other & 1.0 & - \\
\hline KPS score $\geq 70$ & $0.33(0.12-0.86)$ & $0.025^{*}$ \\
\hline \multicolumn{3}{|l|}{ Comorbidities } \\
\hline Smoker & $2.17(0.83-5.70)$ & $0.113^{*}$ \\
\hline Hypertension & $0.47(0.16-1.37)$ & $0.172^{*}$ \\
\hline CAD & $1.62(0.48-5.40)$ & 0.429 \\
\hline VTE & $3.47(0.94-12.71)$ & $0.060^{*}$ \\
\hline Renal disease & $2.04(0.20-20.62)$ & 0.543 \\
\hline DM & $0.79(0.21-2.92)$ & 0.732 \\
\hline Hyperlipidemia & $0.32(0.07-1.48)$ & $0.149^{*}$ \\
\hline COPD & $1.57(0.40-6.11)$ & 0.509 \\
\hline Previous spine RT & $1.58(0.66-3.78)$ & 0.299 \\
\hline Increasing no. of levels & $1.20(1.04-1.38)$ & $0.008^{*}$ \\
\hline \multicolumn{3}{|l|}{ Approach } \\
\hline Anterior & Reference & \\
\hline Posterior & $2.44(0.67-8.84)$ & $0.172^{*}$ \\
\hline Combined & $2.30(0.34-15.56)$ & 0.392 \\
\hline
\end{tabular}

\section{Discussion}

Wound reoperations in this cohort of patients with metastatic spine tumor are potentially devastating due to potential risk for hardware exposure, delay in the administration of systemic treatments, increased costs, and prolonged hospitalizations. To stratify patients' risk and improve outcomes, a better understanding of the factors that predict wound reoperation rates is needed. In a multivariate model, we found that thromboembolic events and number of spinal levels involved are both independently associated with a higher risk for wound reoperation.

Patients undergoing spinal tumor resection are at a high risk for VTE due to the length of the operations and limitations in ambulation function perioperatively. Furthermore, patients with cancer in general experience more hypercoagulability than do patients without cancer, and that predisposes the former group to postoperative VTE. Hemostatic abnormalities that lead to a high incidence of VTE include increased fibrin formation and tumor expression of tissue factor and cancer procoagulant, which can both activate the coagulation cascade. ${ }^{9}$ For patients with metastases, the primary cancer site has been shown to be a significant predictor of the development of a VTE. In terms of absolute numbers, VTEs are most prevalent in patients with lung cancer, with the highest rates in lymphoma, ovarian, and pancreatic carcinoma. ${ }^{17}$ The incidence of asymptomatic VTE after spine surgery approaches $20 \%$,
TABLE 3. Multivariate analysis of factors associated with wound reoperation

\begin{tabular}{lll}
\hline \multicolumn{1}{c}{ Parameter } & OR $(95 \% \mathrm{Cl})$ & p Value \\
\hline KPS score $\geq 70$ & $0.36(0.11-1.13)$ & 0.082 \\
\hline Smoking & $2.15(0.73-6.27)$ & 0.161 \\
\hline Hypertension & $0.28(0.07-1.07)$ & 0.064 \\
\hline VTE & $7.61(1.19-48.5)$ & $0.032^{*}$ \\
\hline Hyperlipidemia & $0.61(0.11-3.23)$ & 0.567 \\
\hline Increasing no. of levels & $1.21(1.03-1.43)$ & $0.018^{*}$ \\
\hline Approach & & \\
\hline Anterior & Reference & \\
\hline Posterior & $1.38(0.32-6.00)$ & 0.651 \\
\hline Combined & $1.34(1.14-12.66)$ & 0.796 \\
\hline
\end{tabular}

* $p<0.05$.

whereas symptomatic pulmonary embolism and deep venous thrombosis typically occur in $<1 \%$ of patients. ${ }^{27,31}$

Increasing age, preoperative walking disability, congestive heart failure, and staged surgeries increase the risk of a VTE after spine surgery. ${ }^{14,28,32}$ Previous studies have shown that the development of VTE after spine surgery is associated with poor outcomes. In a sample of 8617 patients who underwent thoracic or thoracolumbar spinal fusion, VTE was associated with higher hospital costs, longer hospitalizations, and increased morbidity. ${ }^{14}$ In this current study, VTE after spine surgery was associated with an increased risk for wound reoperations by 7.61fold. One explanation for this increased risk for wound reoperations could be that it is due to the fact that patients who develop a VTE are aggressively treated with anticoagulants, which may delay wound healing and can predispose patients to wound complications, as has been shown in previous studies. ${ }^{11,29}$ Thus, to reduce the incidence of wound reoperations, early VTE prophylaxis, which may include early administration of subcutaneous heparin and compression devices, is crucial. ${ }^{5}$

The greater risk for more extensive spinal tumor resections is well known. For instance, although en bloc spondylectomy is not as frequently applicable in the metastatic spine tumor population, in patients who received 4- or 5-level en bloc spondylectomy for the treatment of malignant spine tumors, Luzzati et al. reported at least one major complication in 7 of the 9 patients $(77.8 \%) .{ }^{18}$ Furthermore, in a series of 134 en bloc spinal tumor resections, the number of resected spine segments was a significant predictor of major complications. ${ }^{1}$ Although existing literature has established that the number of spinal levels involved is associated with major complications in general, it was unknown whether multilevel resections were also associated with wound-related complications. In this study, we show that the number of spinal levels involved in the operation is significantly associated with higher rates of wound reoperations, such that for each additional level involved, the risk for wound-related reoperations increased $21 \%$.

Because the metastatic tumor involves more spinal levels, the incision will clearly need to be lengthened to complete the resection. Thus, the length of the incision seems to be an independent risk factor for wound reop- 
eration. One factor that could contribute to the adverse effect of wound lengthening is adjuvant radiation, which disrupts every phase of wound healing. Previous work has demonstrated that adjuvant RT is associated with a higher rate of deep wound infections, wound dehiscence, and delayed wound healing. 1,24 During the inflammatory and proliferative stages of wound healing, radiation alters levels of transforming growth factor- $\beta$, VEGF, and nitrous oxide, leading to uncontrolled matrix accumulation and impaired strength of wounds..$^{16}$ Furthermore, irradiated wounds have a decreased rate of collagen deposition due to the toxic effects on fibroblasts as well as less tolerance of bacterial contamination. ${ }^{20}$ These combined factors lead to delayed healing and a higher incidence of infections. Given that this cohort may already experience diminished wound healing from previous spine radiation $(39.0 \%)$ as well as smoking (43.5\%) and DM (16.1\%), lengthening the wound exaggerates this inherent vulnerability and leads to higher rates of wound breakdown. In patients with spine tumors, wound complications typically require reoperation for irrigation, debridement, and soft-tissue coverage. Because most patients are preparing for or have already started postoperative radiotherapy, interrupting treatment for a wound reoperation could interfere with their ability to fight against their malignancy. ${ }^{22}$

In addition to thromboembolic events and multilevel resections, previous studies have also identified preoperative RT, preoperative corticosteroid administration, nutritional deficiencies, previous spine surgeries, DM, length of hospitalization, and posterior approach as some of the other risk factors for wound complications in metastatic spine surgery. ${ }^{8,20,22,23}$ To mitigate risks for wound complications, a recent review by Mesfin et al. recommended involving a plastic surgeon to perform soft-tissue reconstruction, using intrawound vancomycin, and placing percutaneous pedicle screws. ${ }^{22}$ Since we show that thromboembolic events and increasing number of levels are independently associated with a higher risk for wound reoperations, other ways to prevent wound breakdown after metastatic spine surgery include implementing early multimodal VTE prophylaxis and making only the minimum incision length needed for resection.

Our study has several limitations that warrant discussion. Because our study is retrospective, we have limited ability to make causal conclusions regarding factors associated with wound reoperations. However, this is the largest study to date examining factors associated with wound reoperations after metastatic spine surgery. The heterogeneity of past treatments in our cohort could further limit the conclusions of our study. Finally, additional studies are needed to examine whether wound reoperations are associated with other adverse events such as readmissions, explanted instrumentation, or death.

\section{Conclusions}

Patients who undergo metastatic spine tumor resection are at an inherently high risk for wound-related reoperations due to high rates of adjuvant radiation, various medical comorbidities, and potentially long incisions. In this study, we found that thromboembolic events and number of levels resected are independently associated with a greater risk for wound reoperations. To lower the risk for wound reoperations in this highest-risk subgroup, initiating aggressive VTE prophylaxis and providing meticulous and timely wound care to the longest incisions in particular are crucial interventions.

\section{References}

1. Boriani S, Bandiera S, Donthineni R, Amendola L, Cappuccio M, De Iure F, et al: Morbidity of en bloc resections in the spine. Eur Spine J 19:231-241, 2010

2. Buerba RA, Fu MC, Gruskay JA, Long WD III, Grauer JN: Obese Class III patients at significantly greater risk of multiple complications after lumbar surgery: an analysis of 10,387 patients in the ACS NSQIP database. Spine J 14:2008-2018, 2014

3. Capen DA, Calderone RR, Green A: Perioperative risk factors for wound infections after lower back fusions. Orthop Clin North Am 27:83-86, 1996

4. Chieng LO, Hubbard Z, Salgado CJ, Levi AD, Chim H: Reconstruction of open wounds as a complication of spinal surgery with flaps: a systematic review. Neurosurg Focus 39(4):E17, 2015

5. Cox JB, Weaver KJ, Neal DW, Jacob RP, Hoh DJ: Decreased incidence of venous thromboembolism after spine surgery with early multimodal prophylaxis: Clinical article. J Neurosurg Spine 21:677-684, 2014

6. De la Garza Ramos R, Goodwin CR, Jain A, Abu-Bonsrah N, Fisher CG, Bettegowda C, et al: Development of a metastatic spinal tumor frailty index (MSTFI) using a nationwide database and its association with inpatient morbidity, mortality, and length of stay after spine surgery. World Neurosurg 95:548-555, 555.e1-555.e4, 2016

7. De la Garza Ramos R, Jain A, Nakhla J, Nasser R, Puvanesarajah V, Hassanzadeh H, et al: Postoperative morbidity and mortality after elective anterior cervical fusion in patients with chronic and end-stage renal disease. World Neurosurg 95:480-485, 2016

8. Demura S, Kawahara N, Murakami H, Nambu K, Kato S, Yoshioka K, et al: Surgical site infection in spinal metastasis: risk factors and countermeasures. Spine (Phila Pa 1976) 34:635-639, 2009

9. Dipasco PJ, Misra S, Koniaris LG, Moffat FL Jr: Thrombophilic state in cancer, part I: biology, incidence, and risk factors. J Surg Oncol 104:316-322, 2011

10. Dumanian GA, Ondra SL, Liu J, Schafer MF, Chao JD: Muscle flap salvage of spine wounds with soft tissue defects or infection. Spine (Phila Pa 1976) 28:1203-1211, 2003

11. Ferres MA, Olivarez SA, Trinh V, Davidson C, SangiHaghpeykar H, Aagaard-Tillery KM: Rate of wound complications with enoxaparin use among women at high risk for postpartum thrombosis. Obstet Gynecol 117:119-124, 2011

12. Flexman AM, Charest-Morin R, Stobart L, Street J, Ryerson CJ: Frailty and postoperative outcomes in patients undergoing surgery for degenerative spine disease. Spine J 16:13151323,2016

13. Garvey PB, Rhines LD, Dong W, Chang DW: Immediate soft-tissue reconstruction for complex defects of the spine following surgery for spinal neoplasms. Plast Reconstr Surg 125:1460-1466, 2010

14. Gephart MG, Zygourakis CC, Arrigo RT, Kalanithi PS, Lad SP, Boakye M: Venous thromboembolism after thoracic/ thoracolumbar spinal fusion. World Neurosurg 78:545-552, 2012

15. Gilbert RW, Kim JH, Posner JB: Epidural spinal cord compression from metastatic tumor: diagnosis and treatment. Ann Neurol 3:40-51, 1978 
16. Haubner F, Ohmann E, Pohl F, Strutz J, Gassner HG: Wound healing after radiation therapy: review of the literature. Radiat Oncol 7:162, 2012

17. Levitan N, Dowlati A, Remick SC, Tahsildar HI, Sivinski LD, Beyth R, et al: Rates of initial and recurrent thromboembolic disease among patients with malignancy versus those without malignancy. Risk analysis using Medicare claims data. Medicine (Baltimore) 78:285-291, 1999

18. Luzzati AD, Shah SP, Gagliano FS, Perrucchini GG, Fontanella W, Alloisio M: Four- and five-level en bloc spondylectomy for malignant spinal tumors. Spine (Phila Pa 1976) 39:E129-E139, 2014

19. Maccauro G, Spinelli MS, Mauro S, Perisano C, Graci C, Rosa MA: Physiopathology of spine metastasis. Int J Surg Oncol 2011:107969, 2011

20. McPhee IB, Williams RP, Swanson CE: Factors influencing wound healing after surgery for metastatic disease of the spine. Spine (Phila Pa 1976) 23:726-733, 1998

21. Mericli AF, Tarola NA, Moore JH Jr, Copit SE, Fox JW IV, Tuma GA: Paraspinous muscle flap reconstruction of complex midline back wounds: risk factors and postreconstruction complications. Ann Plast Surg 65:219-224, 2010

22. Mesfin A, Sciubba DM, Dea N, Nater A, Bird JE, Quraishi NA, et al: Changing the adverse event profile in metastatic spine surgery: an evidence-based approach to target wound complications and instrumentation failure. Spine (Phila Pa 1976) 41 (Suppl 20):S262-S270, 2016

23. Omeis IA, Dhir M, Sciubba DM, Gottfried ON, McGirt MJ, Attenello FJ, et al: Postoperative surgical site infections in patients undergoing spinal tumor surgery: incidence and risk factors. Spine (Phila Pa 1976) 36:1410-1419, 2011

24. Pascal-Moussellard H, Broc G, Pointillart V, Siméon F, Vital JM, Sénégas J: Complications of vertebral metastasis surgery. Eur Spine J 7:438-444, 1998

25. Quraishi NA, Esler C: Metastatic spinal cord compression. BMJ 342:d2402, 2011

26. Quraishi NA, Rajabian A, Spencer A, Arealis G, Mehdian H, Boszczyk BM, et al: Reoperation rates in the surgical treatment of spinal metastases. Spine J 15 (3 Suppl):S37-S43, 2015

27. Rokito SE, Schwartz MC, Neuwirth MG: Deep vein thrombosis after major reconstructive spinal surgery. Spine (Phila Pa 1976) 21:853-859, 1996

28. Sebastian AS, Currier BL, Clarke MJ, Larson D, Huddleston PM III, Nassr A: Thromboembolic disease after cervical spine surgery: a review of 5,405 surgical procedures and matched cohort analysis. Global Spine J 6:465-471, 2016

29. Sindali K, Rose B, Soueid H, Jeer P, Saran D, Shrivastava R: Elective hip and knee arthroplasty and the effect of rivaroxaban and enoxaparin thromboprophylaxis on wound healing. Eur J Orthop Surg Traumatol 23:481-486, 2013

30. Sundaresan N, Rothman A, Manhart K, Kelliher K: Surgery for solitary metastases of the spine: rationale and results of treatment. Spine (Phila Pa 1976) 27:1802-1806, 2002

31. Takahashi H, Yokoyama Y, Iida Y, Terashima F, Hasegawa $\mathrm{K}$, Saito T, et al: Incidence of venous thromboembolism after spine surgery. J Orthop Sci 17:114-117, 2012
32. Tominaga H, Setoguchi T, Tanabe F, Kawamura I, Tsuneyoshi Y, Kawabata N, et al: Risk factors for venous thromboembolism after spine surgery. Medicine (Baltimore) 94:e466, 2015

33. Weigel B, Maghsudi M, Neumann C, Kretschmer R, Müller FJ, Nerlich M: Surgical management of symptomatic spinal metastases. Postoperative outcome and quality of life. Spine (Phila Pa 1976) 24:2240-2246, 1999

34. Wise JJ, Fischgrund JS, Herkowitz HN, Montgomery D, Kurz LT: Complication, survival rates, and risk factors of surgery for metastatic disease of the spine. Spine (Phila Pa 1976) 24:1943-1951, 1999

\section{Disclosures}

Mr. Ahmed had a Neurosurgery Research and Education Foundation (NREF) Medical Student Summer Research Fellowship. Dr. Goodwin is a United Negro College Fund (UNCF) Merck Postdoctoral Fellow and has received an award from the Burroughs Wellcome Fund, the NIH/NINDS Neurosurgeon Research Career Development Program (NRCDP) K12 Physician Scientist Award, and the North Carolina Spine Society. Dr. Bydon has a research grant from DePuy Spine and serves on the clinical advisory board of MedImmune, LLC. Dr. Witham receives support of a non-study-related clinical or research effort that he oversees in a grant from Eli Lilly and Co., and from the Gordon and Marilyn Macklin Foundation. Dr. Gokaslan has stock ownership in US Spine and Spinal Kinetics; receives consulting, speaking, and teaching fees from the AO Foundation; and receives research support from DePuy, NREF, AOSpine, and AO North America. Dr. Sacks has a consulting relationship with LifeCell, Inc. Dr. Sciubba has consulting relationships with Medtronic, Globus, DePuy-Synthes, Stryker, K2M, and NuVasive.

\section{Author Contributions}

Conception and design: Goodwin, Carl, Abu-Bonsrah, De la Garza Ramos, Sciubba. Acquisition of data: Goodwin, Ahmed, Abu-Bonsrah, De la Garza Ramos, Sankey, Pennington. Analysis and interpretation of data: Goodwin, Carl, Ahmed, Abu-Bonsrah, De la Garza Ramos, Sankey. Drafting the article: Goodwin, Carl, Ahmed, Abu-Bonsrah, De la Garza Ramos, Bydon, Witham, Wolinsky, Gokaslan, Sacks. Critically revising the article: Goodwin, Carl, Ahmed, Abu-Bonsrah, De la Garza Ramos, Bydon, Witham, Wolinsky, Gokaslan, Sacks, Sciubba. Reviewed submitted version of manuscript: Goodwin, Carl, Abu-Bonsrah, Sankey, Bydon, Witham, Wolinsky, Gokaslan, Sacks, Sciubba. Statistical analysis: Goodwin, Carl, Ahmed, De la Garza Ramos. Administrative/technical/material support: Sciubba. Study supervision: Goodwin, Bydon, Witham, Wolinsky, Gokaslan, Sacks, Sciubba.

\section{Correspondence}

C. Rory Goodwin: Duke University Medical Center, Durham, NC. rory.goodwin@duke.edu. 